\title{
Sulforaphane sensitizes human breast cancer cells to paclitaxel-induced apoptosis by downregulating the NF-кB signaling pathway
}

\author{
SEUNG-HYUN KIM, HYUN-JUNG PARK and DONG-OH MOON \\ Department of Biology Education, Daegu University, Gyeongsan, Gyeongsang 38453, Republic of Korea
}

Received July 22, 2015; Accepted November 3, 2016

DOI: $10.3892 / \mathrm{ol} .2017 .5950$

\begin{abstract}
Sulforaphane (SFN), an isothiocyanate present in cruciferous vegetables, has been demonstrated to inhibit the growth of various types of cancer cell. The aim of the present study was to investigate whether SFN sensitizes breast cancer cells to paclitaxel-induced apoptosis and to identify the signal pathway through which SFN mediates apoptosis. Combined treatment of breast cancer cells with SFN and paclitaxel resulted in increased activation of apoptotic signaling pathway members, including caspase-3, -8 and -9 , and cytochrome $c$, compared with treatment with SFN or paclitaxel alone. In addition, treatment with SFN and paclitaxel resulted in downregulation of the nuclear factor kappa B signaling pathway, and reduced protein expression of apoptosis regulator Bcl-2 and phosphorylated AKT serine/threonine kinase. Furthermore, SFN-paclitaxel-induced apoptosis was inhibited by overexpression of Bcl-2. The results of the present study suggest that combined treatment with SFN and paclitaxel is a novel therapeutic strategy for the treatment of breast cancer.
\end{abstract}

\section{Introduction}

Breast cancer is the most prevalent cancer in females worldwide, with an overall lifetime risk of $>10 \%$ (1). Paclitaxel, isolated from the bark of Taxus brevifolia, is a potent chemotherapeutic agent used in the treatment of breast cancer (2). Paclitaxel mechanistically interferes with the dynamic instability of microtubules, leading to G2/M cell cycle arrest and subsequent apoptosis (3). However, paclitaxel chemotherapy has had limited success (4) due to the activation of cytoprotective signaling pathways in tumors, including the nuclear factor kappa B (NF-kB), AKT serine/threonine kinase (Akt) and mitogen-activated protein kinase signaling pathways, which

Correspondence to: Professor Dong-Oh Moon, Department of Biology Education, Daegu University, 201 Daegudae Street, Gyeongsan, Gyeongsang 38453, Republic of Korea

E-mail: domoon@daegu.ac.kr

Key words: sulforaphane, paclitaxel, apoptosis, BCL2, apoptosis regulator, nuclear factor kappa $\mathrm{B}$ induce drug resistance (3-6). In addition, paclitaxel has been implicated in the regulation of $\mathrm{NF}-\kappa \mathrm{B}$-dependent genes that promote cell survival and inhibit apoptosis, including apoptosis regulator $\mathrm{Bcl}-2$ and $\mathrm{Bcl}-2$ like 1 (Bcl-xL) (7). Therefore, agents that inhibit paclitaxel-induced $\mathrm{NF}-\kappa \mathrm{B}$ activation may be effective chemotherapeutic candidates for the treatment of breast cancer.

Sulforaphane (SFN), an isothiocyanate naturally present in cruciferous vegetables, including broccoli, sprouts and kale, has been reported to reduce the risk of developing a number of common types of cancer, including breast cancer $(8,9)$. Previous studies have demonstrated that SFN induces G2/M cell cycle arrest by elevating cyclin $\mathrm{B} 1$ expression, and induces apoptosis by activating poly(ADP-ribose) polymerase 1 and caspase family proteins in human breast cancer cell lines $(8,10)$. In addition, SFN was reported to attenuate histone deacetylase activity in prostate epithelial cells (11) and inhibit tubulin polymerization in breast cancer cells (12). Furthermore, SFN has been demonstrated to inhibit $\mathrm{NF}-\kappa \mathrm{B}$ activation in various diseases, including cancer, skin disorders and spinal cord injury, by inhibiting NF- $\kappa \mathrm{B}$ inhibitor alpha $(\mathrm{I} \kappa \mathrm{B} \alpha)$ phosphorylation, I $\kappa \mathrm{B} \alpha$ degradation and p65 nuclear translocation (13). Therefore, SFN may be an effective chemotherapeutic agent.

Building upon previous paclitaxel and SFN research, the present study investigated the effect of combined SFN-paclitaxel treatment on breast cancer cells. The underlying molecular mechanisms of combined SFN and paclitaxel treatment were investigated by evaluating the inhibition of the anti-apoptotic signal transducers Akt and NF- $\kappa$ B. It was observed that treatment with SFN inhibits paclitaxel-induced $\mathrm{NF}-\kappa \mathrm{B}$ activation, $\mathrm{Bcl}-2$ gene expression and proliferation in breast cancer cells.

\section{Materials and methods}

Cell culture. The human breast cancer cell lines MDA-MB-231 and MCF-7 were purchased from the American Type Culture Collection (Manassas, VA, USA). Cells were cultured in Dulbecco's modified Eagle's medium supplemented with $10 \%$ fetal bovine serum (Gibco; Thermo Fisher Scientific, Inc., Waltham, MA, USA) and antibiotics (100 $\mu \mathrm{g} / \mathrm{ml}$ streptomycin and $100 \mathrm{U} / \mathrm{ml}$ penicillin; Thermo Fisher Scientific, Inc.), and maintained at $37^{\circ} \mathrm{C}$ in a humidified atmosphere containing $5 \% \mathrm{CO}_{2}$. Overexpression of $\mathrm{Bcl}-2$ was induced by transfecting 
a PC3.1-Bcl-2 plasmid into MDA-MB-231 cells with Lipofectamine ${ }^{\circledR} 2000$ (Invitrogen; Thermo Fisher Scientific, Inc.): At 1 day prior to transfection, $1 \times 10^{5}$ cells in $500 \mu \mathrm{l}$ of growth medium without antibiotics were seeded in each well of a 24-well plate. When 90-95\% confluence was obtained, $0.8 \mu \mathrm{g}$ of the PC3.1-Bcl-2 plasmid in serum-free $50 \mu$ l Opti-MEM I (cat. no. 31985; Invitrogen; Thermo Fisher Scientific, Inc.) was prepared, and $2 \mu \mathrm{l}$ of Lipofectamine ${ }^{\circledR} 2000$ was diluted with $50 \mu \mathrm{l}$ of Opti-MEM I. After waiting $5 \mathrm{~min}$, the diluted Lipofectamine ${ }^{\circledR} 2000$ was combined with the diluted PC3.1-Bcl-2 plasmid for a total volume of $100 \mu \mathrm{l}$, gently mixed, and left to stand for $20 \mathrm{~min}$ at room temperature. The $100 \mu \mathrm{l}$ volume was then added to each well. Following transfection, a stable $\mathrm{Bcl}-2$-overexpressing cell line was generated using neomycin $(1000 \mu \mathrm{g} / \mu \mathrm{l})$ to select cells. Cells were then maintained at $37^{\circ} \mathrm{C}$, in a humidified atmosphere with $5 \% \mathrm{CO}_{2}$.

Reagents. Propidium iodide (PI), MTT, paclitaxel and SFN were obtained from Sigma-Aldrich (Merck KGaA, Darmstadt, Germany). The Caspase 3, 8 and 9 Fluorometric Assay kit was obtained from R\&D Systems, Inc. (Minneapolis, MN, USA). The rabbit anti-human primary antibodies anti-Bcl-2 (cat no. MABC573), cytochrome $c$ (cat no. 04-1043), caspase-3 (cat no. AB1899), caspase-8 (cat no. 06-775) and caspase-9 (cat no. AB16969) were purchased from Calbiochem ( $\mathrm{La}$ Jolla, CA, USA). The rabbit anti-human primary antibodies directed against Akt (cat no. 4691), phosphorylated (P)-Akt (cat no. 4060), IкB $\alpha$ (cat no. 4812), GADPH (cat. no. 5174) and P-IкB kinase (P-IKK) (cat no. 2697) were purchased from Cell Signaling Technology, Inc. (Danvers, MA, USA). The primary antibodies were used at a dilution of 1:1,000. All other chemicals not specifically cited here were purchased from Sigma-Aldrich (Merck Millipore).

Cell viability assay. Cells were grown to $70 \%$ confluence and treated with increasing concentrations $(0-20 \mu \mathrm{M})$ of SFN, alone or in combination with $10 \mathrm{nM}$ paclitaxel. Control untreated cells were incubated, with complete media containing $0.1 \%$ dimethyl sulfoxide, at $37^{\circ} \mathrm{C}$ with $5 \% \mathrm{CO}_{2}$ in a humidified atmosphere, for $24 \mathrm{~h}$. Following treatment, cell number and viability was determined using an MTT assay. A volume of $200 \mu \mathrm{l}$ DMEM containing $2 \times 10^{4}$ cells was seeded in each well of 48-well plates. Following treatment with SFN and paclitaxel, the plates were incubated for 2 days. For each measurement, $50 \mu \mathrm{l}$ MTT $(5 \mathrm{mg} / \mathrm{ml})$ was added into each well and incubated at $37^{\circ} \mathrm{C}$ with $5 \% \mathrm{CO}_{2}$ for $2 \mathrm{~h}$. The wells were then decanted, and formed formazan crystals were dissolved in $200 \mu \mathrm{l}$ DMSO. The absorbance of the plate was measured at $595 \mathrm{~nm}$ in an ELISA plate reader. A hemocytometer was additionally used for viable cell counts. All assays were performed in triplicate.

Flow cytometric analysis. Cells were seeded in 6-well plates at a density of $2 \times 10^{5}$ cells/well and subsequently treated with increasing concentrations $(0-20 \mu \mathrm{M})$ SFN and paclitaxel alone, or combined, at $37^{\circ} \mathrm{C}$ for $24 \mathrm{~h}$. Treated and control cells were harvested by trypsinization and stained with PI, according to the manufacturer's protocol. Cell cycle progression was determined using flow cytometry (FACSCalibur ${ }^{\mathrm{TM}}$; BD Biosciences, Franklin Lakes, NJ, USA) and data analysis was performed using FlowJo 9.3 software for Mac OS X (Tree Star, Inc., Ashland, OR, USA). To detect apoptosis, cells were harvested and stained using the Annexin-V Apoptosis Detection kit (R\&D Systems, Inc.) In brief, the cells were harvested and washed with cold PBS, centrifuged at $\sim 300 \mathrm{x} g$ for 5 to $10 \mathrm{~min}$ at room temperature, resuspended in $100 \mu \mathrm{l}$ of the binding buffer from the kit containing $2.5 \mu 1$ FITC conjugated Annexin- $\mathrm{V}$ and incubated for $15 \mathrm{~min}$ at room temperature in the dark. A total of $>10,000$ events were detected and analyzed by flow cytometry.

Mitochondrial labelling within live cells. SFN-treated cells were stained with $1 \mu \mathrm{g} / \mathrm{ml}$ MitoTracker for $15 \mathrm{~min}$ and observed under a fluorescence microscope. Samples were then further analyzed by FACScan (BD Biosciences). Data analysis was performed using FlowJo 9.3 software (Tree Star, Inc.).

Western blotting. Cells were washed with cold PBS and lysed in a commercial lysis buffer PRO-PREP ${ }^{\circledR}$ (Intron Biotechnology Inc., Seongnam, Korea). Protein concentration was determined using a Bio-Rad Protein Assay kit II (cat. no. 5000002; Bio-Rad Laboratories, Inc., Hercules, CA, USA) according to the manufacturer's protocol. Total protein $(30 \mu \mathrm{g})$ was separated using 12\% SDS-PAGE and transferred to a nitrocellulose membrane (Schleicher \& Schuell BioScience, Inc., Keene, NH, USA). The primary antibodies were incubated with the membrane at $4^{\circ} \mathrm{C}$ overnight. Membranes were then washed and incubated with $5 \%$ skimmed milk in tris-buffered saline with Tween 20 for $1 \mathrm{~h}$. Anti-rabbit IgG conjugated to horseradish peroxidase (cat no. 7074; Cell Signaling Technology, Inc.) was used as the secondary antibody. The secondary antibody (dilution, 1:2,000) was incubated at room temperature, for $1 \mathrm{~h}$. Protein bands were visualized using an Amersham Imager 600 enhanced chemiluminescence detection system (GE Healthcare Life Sciences, Chalfont, UK). GADPH was used as a protein loading control.

Preparation of cytosolic extracts. Cells were harvested by gentle scraping and washed in PBS. For preparation of cytosolic extracts, cells were resuspended in ice-cold lysis buffer (250 mM sucrose, $80 \mathrm{mM} \mathrm{KCl,} 50 \mu \mathrm{g} / \mathrm{ml}$ digitonin, PMSF, and complete ${ }^{\mathrm{TM}}$ protease inhibitor in PBS). Following $5 \mathrm{~min}$ of incubation on ice the cell suspensions were centrifuged at $10,000 \times \mathrm{g}$ for $5 \mathrm{~min}$ at $-20^{\circ} \mathrm{C}$ and the supernatants were frozen at $-70^{\circ} \mathrm{C}$ until analysis by western blotting.

Electrophoretic mobility shift assay (EMSA). EMSA was performed on nuclear extracts. Briefly, the preparation of nuclear extracts was conducted using NE-PER nuclear extraction reagents (Pierce; Thermo Fisher Scientific, Inc.) according to the manufacturer's protocol. Briefly, MDA-MB231 cells treated with SFN and paclitaxel, were harvested using trypsin-EDTA and subsequently washed with PBS. Cytosolic proteins were first extracted by disrupting the cell membranes, followed by centrifugation at $16,000 \times \mathrm{g}$ for $5 \mathrm{~min}$ at $-20^{\circ} \mathrm{C}$. Intact nuclei were washed with cold PBS and then lysed with high salt NE-PER buffer. Nuclear fractions were stored at $-80^{\circ} \mathrm{C}$ for use in subsequent experiments. A synthetic complementary NF- $\mathrm{NB}$-binding oligonucleotide (5'-AGT TGA GGG GAC TTT CCC AGG C-3'; Santa Cruz Biotechnology, 

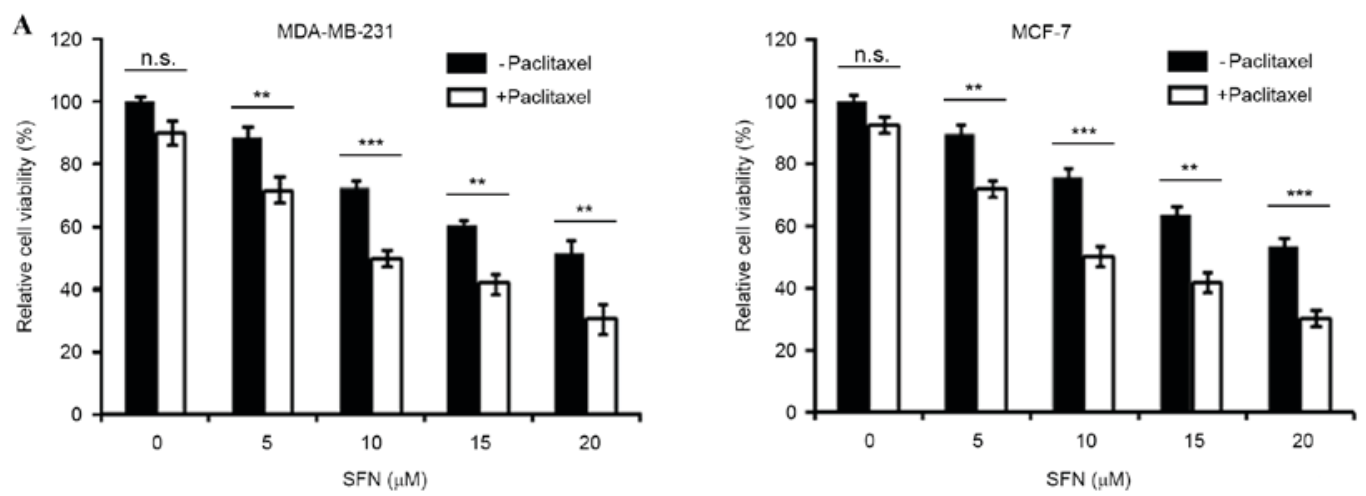

B

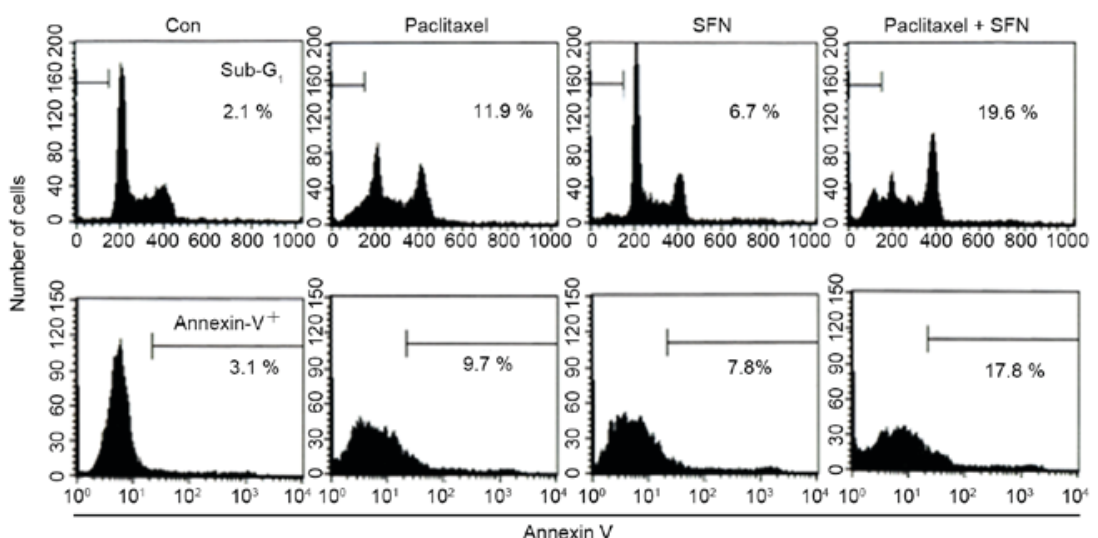

Figure 1. SFN enhances paclitaxel-induced apoptosis in breast cancer cells. (A) Human breast cancer MDA-MB231 and MCF-7 cell lines were treated with increasing $(0-20 \mu \mathrm{M}) \mathrm{SFN}$ concentrations with or without $10 \mathrm{nM}$ paclitaxel for $24 \mathrm{~h}$. The MTT assay was used to assess cell viability and the results were normalized to the untreated control cells. (B) MDA-MB-231 cells were treated with $10 \mathrm{nM}$ paclitaxel alone, $5 \mu \mathrm{M}$ SFN alone, or $10 \mathrm{nM}$ paclitaxel and $5 \mu \mathrm{M}$ SFN for $24 \mathrm{~h}$. Flow cytometry was used to analyze sub-G1 DNA content (upper panel) and positive Annexin V staining (lower panel). Values are presented as means \pm standard deviation of triplicate results. ${ }^{*} \mathrm{P}<0.05$ vs. Con cells. SFN, sulforaphane; Con, untreated control.

Inc., Dallas, TX, USA) was 3'-biotinylated with a Pierce Biotin 3' End DNA Labeling kit used according to the manufacturer's protocol (Thermo Fisher Scientific, Inc.). Binding reactions were conducted with $50 \mathrm{ng} / \mu \mathrm{l}$ poly $(\mathrm{dI}-\mathrm{dC}), 0.05 \%$ Nonidet P-40, $5 \mathrm{mM} \mathrm{MgCl} 2,10 \mathrm{mM}$ EDTA and $2.5 \%$ glycerol in $1 \mathrm{X}$ binding buffer (Pierce LightShift ${ }^{\mathrm{TM}}$ Chemiluminescent EMSA kit, Thermo Fisher Scientific, Inc.), using $20 \mathrm{fmol}$ of biotin-end-labeled target DNA and $10 \mu \mathrm{g}$ of nuclear extract, for $20 \mathrm{~min}$ at room temperature. Assays were loaded onto native $4 \%$ polyacrylamide gels, pre-electrophoresed for $60 \mathrm{~min}$ in $0.5 \mathrm{X}$ Tris borate in EDTA and electrophoresed at $100 \mathrm{~V}$, followed by transfer onto a positively charged nylon membrane (Hybond ${ }^{\mathrm{TM}}-\mathrm{N}^{+}$; GE Healthcare Life Sciences) in 0.5x Tris borate/EDTA at $100 \mathrm{~V}$ for $30 \mathrm{~min}$. Transferred DNAs were cross-linked to the membrane at $120 \mathrm{~mJ} / \mathrm{cm}^{2}$ and detected using horseradish peroxidase-conjugated streptavidin (from the LightShift ${ }^{\mathrm{TM}}$ Chemiluminescent EMSA kit) according to the manufacturer's instructions.

Determination of caspase activity. Caspase activity was determined using the Caspase 3, 8 and 9 Fluorometric Assay kit (R\&D Systems, Inc.) according to the manufacturer's protocol. The kit utilized synthetic tetrapeptides labeled with P-nitroaniline. Cells were lysed in the supplied lysis buffer, and supernatants were collected by centrifugation $(10,000 \mathrm{x} g$, $20 \mathrm{~min}, 4^{\circ} \mathrm{C}$ ), then incubated at $37^{\circ} \mathrm{C}$ with the supplied reaction buffer. Caspase activity was determined by measuring the change in absorbance at $405 \mathrm{~nm}$ with a microplate reader.
Statistical analysis. Values are presented as the mean \pm standard deviation of triplicate data. The statistical significance of differences was assessed using a two-way ANOVA followed by Bonferroni's multiple comparison test. GraphPad Software 6 was used for statistical analyses (GraphPad Software Inc., La Jolla, CA, USA). $\mathrm{P}<0.05$ was considered to indicate a statistically significant difference; $\mathrm{P}<0.01$ and $\mathrm{P}<0.001$ were additionally considered as further thresholds of significance.

\section{Results}

Combined treatment with SFN and paclitaxel reduces human breast cancer cell viability. The effect of paclitaxel on cell viability was analyzed in MDA-MB-231 and MCF-7 breast cancer cell lines. Treatment with $10 \mathrm{nM}$ paclitaxel induced limited inhibition of cell viability $(<10 \%)$ at $24 \mathrm{~h}$, suggesting that these cells are resistant to the apoptotic effects of paclitaxel. The effect of combined treatment with SFN and paclitaxel on cell viability was also examined. Cell viability was significantly decreased by combined treatment with SFN and paclitaxel (MDA-MB231, $\mathrm{P}=0.001,0.0001,0.009,0.001$, respectively; MCF-7, $\mathrm{P}=0.005,0.001,0.004,0.0002$, respectively, for paclitaxel with SFN doses 5, 10, 15 and $20 \mu \mathrm{M}$, compared with SFN-only groups; Fig. 1A). The dependence of combined SFN and paclitaxel treatment on apoptosis was subsequently investigated. As shown in Fig. 1B, treatment of MDA-MB2-31 cells with $5 \mu \mathrm{M}$ SFN and $10 \mathrm{nM}$ paclitaxel for $24 \mathrm{~h}$ markedly increased the accumulation of sub-G1 phase 


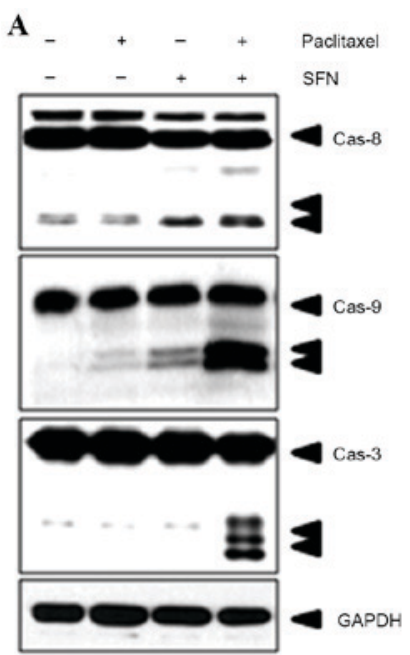

B
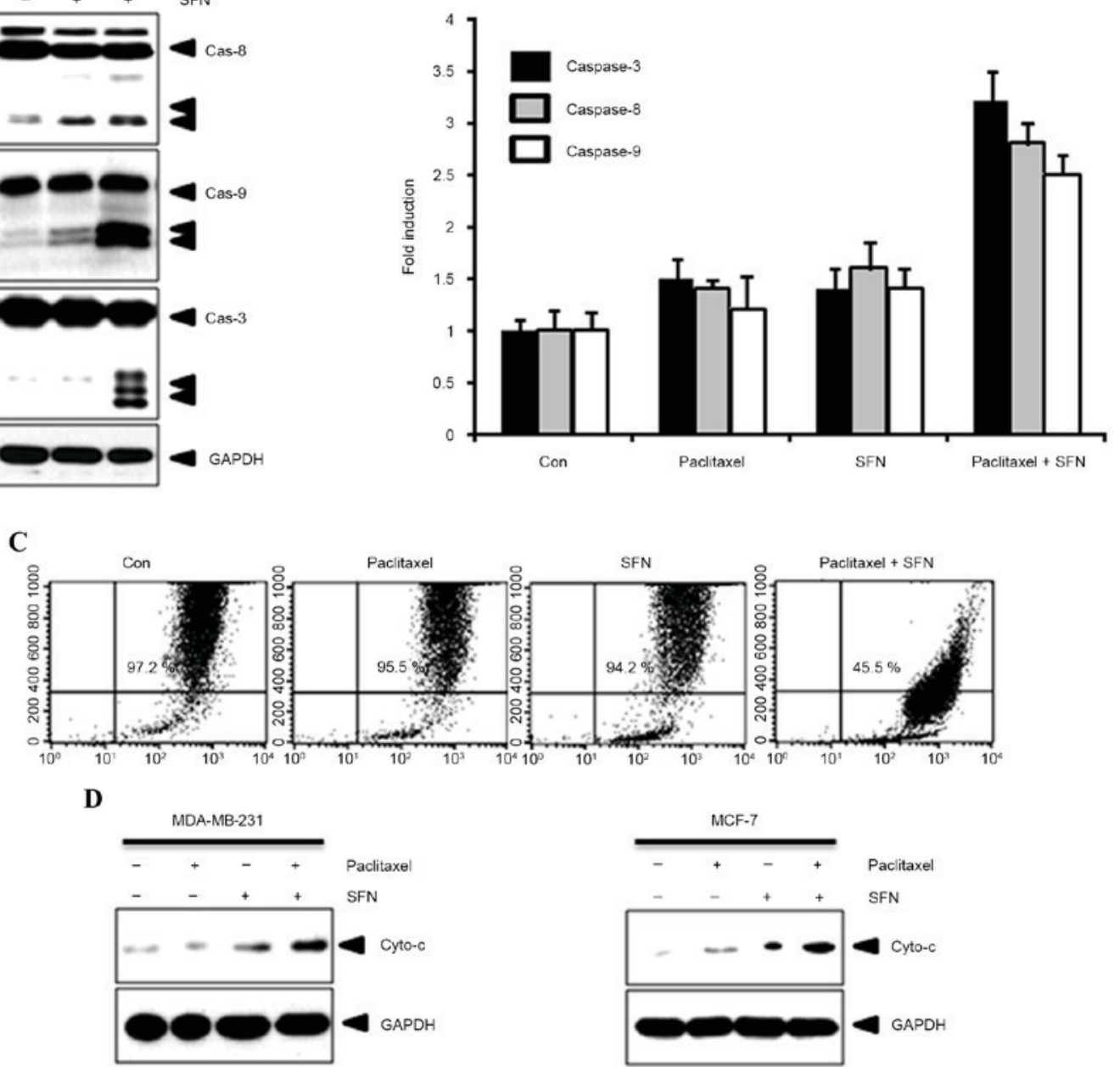

Figure 2. Treatment with a combination of SFN and paclitaxel activates extrinsic and intrinsic apoptotic signaling. (A) MDA-MB-231 cells treated with $5 \mu \mathrm{M}$ SFN alone, $10 \mathrm{nM}$ paclitaxel alone, or $10 \mathrm{mM}$ paclitaxel and $5 \mu \mathrm{M} \mathrm{SFN}$ for $24 \mathrm{~h}$. Subsequent western blotting for caspase- $-8,-9$ and -3 was performed. (B) Caspase activity relative to the Con cells was determined. (C) Mitochondrial membrane potential was measured using flow cytometry and a 3,3'-dihexyloxacarbocyanine iodide dye. (D) The extent of cytochrome $c$ translocation into the cytosol was analyzed with western blotting. SFN, sulforaphane; Cas, caspase; Con, control; Cyto, cytochrome.

cells and Annexin V staining (Fig. 1B). These results indicate that SFN enhances paclitaxel-induced apoptosis and reduces viability in breast cancer cells.

Combined SFN-paclitaxel treatment activates extrinsic and intrinsic apoptotic pathways. To confirm the effect of combined treatment with SFN and paclitaxel on apoptosis, caspase- $8,-9$ and -3 expression and activity was evaluated using western blotting and caspase activity kits, respectively. As shown in Fig. 2A, cleavage of caspase-8, -9 and -3 was observed following treatment with SFN and paclitaxel. By contrast, cleaved caspases were not observed in cells treated with SFN or paclitaxel alone. Furthermore, caspase activity was increased following treatment with SFN and paclitaxel (Fig. 2B). Apoptotic events in the mitochondria were detected by measuring the mitochondrial membrane potential with 3,3'-dihexyloxacarbocyanine iodide. A marked reduction in mitochondrial membrane potential was observed in cells following treatment with SFN and paclitaxel (Fig. 2C). In addition, this process was accompanied by the release of cytochrome $c$ from the mitochondria into the cytosol (Fig. 2D).
These results indicate that combined SFN-paclitaxel treatment increases apoptosis in breast cancer cells.

SFN inhibits paclitaxel-induced NF- $\kappa B$ activation and $I \kappa B \alpha$ degradation. The effect of treatment with SFN on paclitaxel-mediated NF- $\mathrm{KB}$ activation was evaluated using an EMSA. As shown in Fig. 3A, $10 \mathrm{nM}$ paclitaxel induced an increase in NF- $\mathrm{kB}$ binding to complementary oligonucleotides after $15 \mathrm{~min}$, which was sustained for $1 \mathrm{~h}$. Pretreatment with SFN inhibited paclitaxel-induced NF- $\mathrm{\kappa B}$ activation in a time-dependent manner (Fig. 3A). To confirm whether paclitaxel-induced NF- $\mathrm{KB}$ activation was caused by IKK phosphorylation and $\mathrm{I} \kappa \mathrm{B} \alpha$ degradation, western blotting of P-IKK and IкB $\alpha$ was performed. As shown in Fig. 3B, IKK phosphorylation and IкB $\alpha$ degradation began 15 min following treatment with paclitaxel, but was markedly decreased following pretreatment with SFN. These results suggest that paclitaxel induces NF- $\mathrm{KB}$ activation in MDA-MB-231 cells through the degradation of $\mathrm{I} \kappa \mathrm{B} \alpha$ and that SFN inhibits $\mathrm{I} \kappa \mathrm{B} \alpha$ degradation. Since Akt signaling was previously demonstrated to regulate NF- $\mathrm{kB}$ activation $(5,14)$, it was evaluated in the present study whether SFN had an effect on 

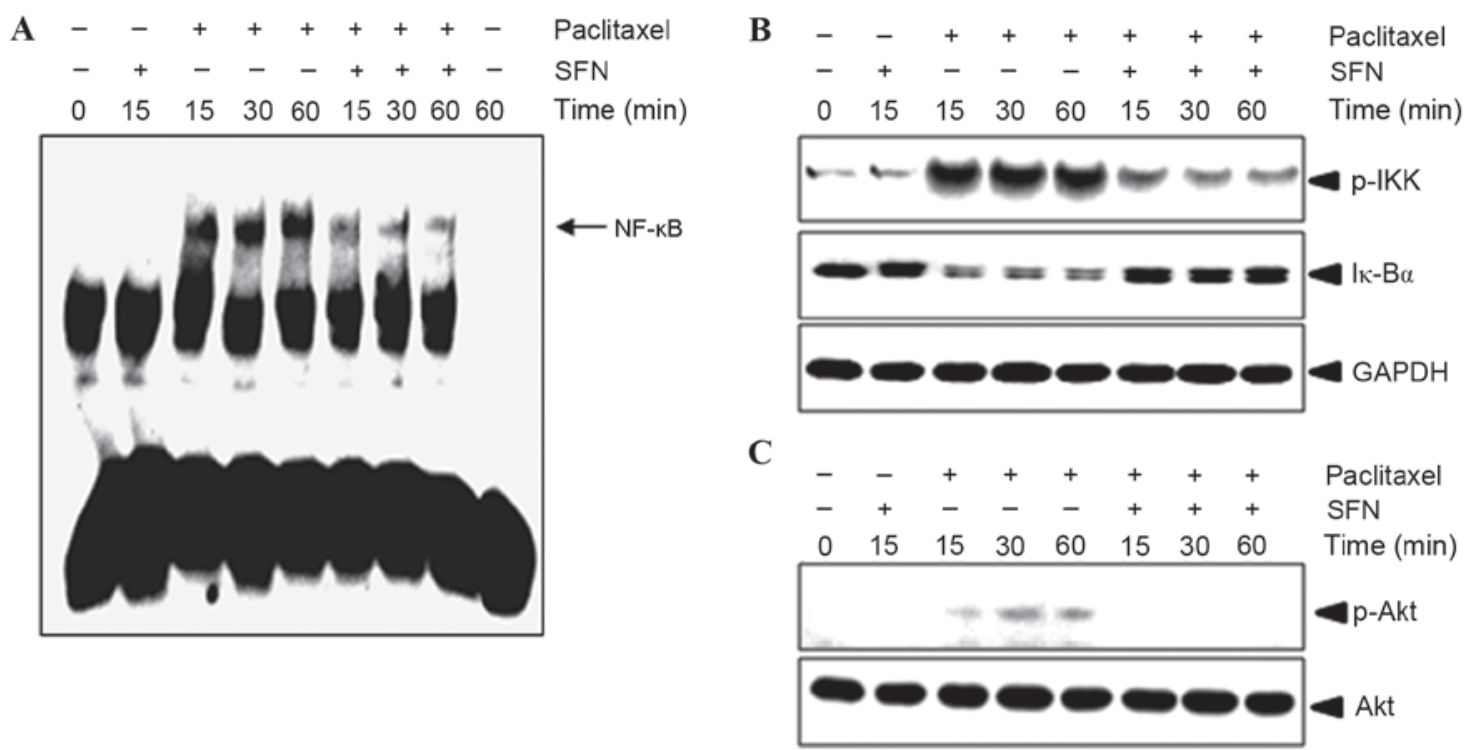

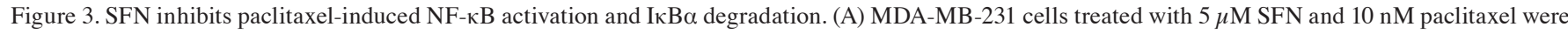

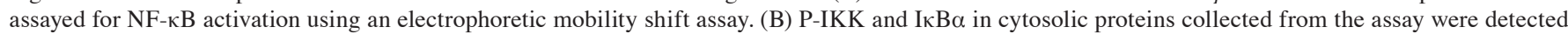
using a western blot. GAPDH was used as the loading control. (C) Whole cell lysates were resolved on a 10\% SDS gel and P-Akt S473 was detected with

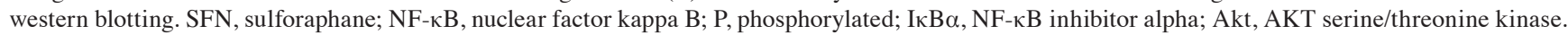
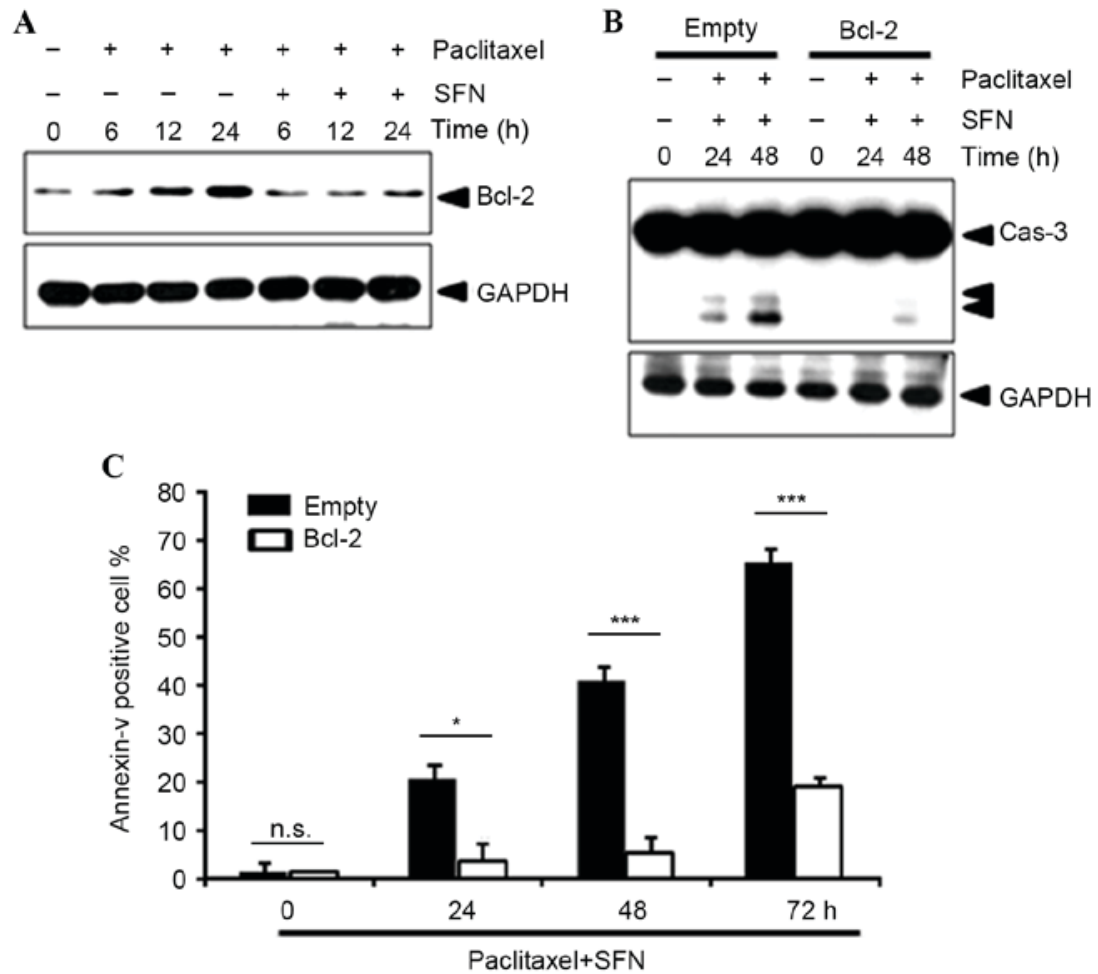

Figure 4. Bcl-2 serves a role in SFN/paclitaxel-induced apoptosis. (A) Western blot analysis of Bcl-2 protein expression in MDA-MB-231 cells treated with $5 \mu \mathrm{M}$ SFN alone, $10 \mathrm{nM}$ paclitaxel alone, or $10 \mathrm{nM}$ paclitaxel and $5 \mu \mathrm{M}$ SFN for $24 \mathrm{~h}$. (B) MDA-MB-231 cells transfected with Bcl-2 or the vector control were analyzed for activated Cas-3 using western blot analysis. (C) Flow cytometric analysis of positive Annexin V staining. "P<0.05; ${ }^{* * * *} \mathrm{P}<0.001$. SFN, sulforaphane; Cas, caspase.

the phosphorylation of AKT. Pretreatment with SFN abolished paclitaxel-induced Akt phosphorylation (Fig. 3C), indicating that Akt serves a role in the mechanism of action of SFN.

Bcl-2 overexpression attenuates paclitaxel-and SFN-induced apoptosis. The level of protein expression of the NF- $\kappa \mathrm{B}$-dependent survival gene Bcl-2 was examined using western blotting. This demonstrated that pretreatment with SFN markedly decreased Bcl-2 protein expression (Fig. 4A), suggesting that SFN-mediated NF- $\kappa \mathrm{B}$ inhibition leads to repression of Bcl-2 expression. In addition, overexpression of Bcl-2 notably inhibited paclitaxel/ SFN-induced caspase-3 activation (Fig. 4B) and significantly inhibited Annexin V staining $(\mathrm{P}=0.033,0.0001,0.0001$, at 24, 48 and 72 h, respectively; Fig. 4C). 


\section{Discussion}

Paclitaxel, a microtubule stabilizer, is frequently used as a chemotherapeutic agent in the treatment of various types of human carcinoma, including breast cancer (2). However, paclitaxel frequently induces drug resistance (2-5). The present study investigated the synergistic anticancer effect of combined treatment with SFN and paclitaxel in human breast cancer cells. Co-treatment with SFN enhanced paclitaxel-induced apoptosis via increased activation of caspase-3,-8 and -9. Additionally, co-treatment with SFN inhibited paclitaxel-induced $\mathrm{NF}-\kappa \mathrm{B}$ activation, Bcl-2 expression and Akt phosphorylation in MDA-MB-231 cells. The results of the present study suggest that SFN and paclitaxel exhibit chemopreventive activity by inducing breast cancer cell apoptosis.

$\mathrm{NF}-\kappa \mathrm{B}$ is a ubiquitously-expressed transcription factor that regulates the expression of various genes associated with cell proliferation, metastasis, cell cycle progression, angiogenesis and apoptosis. Furthermore, the role of NF- $\kappa \mathrm{B}$ in chemoresistance is well-established $(15,16)$. Paclitaxel may activate $\mathrm{NF}-\kappa \mathrm{B}$ through activation of its primary kinase, IKK $(2,3)$. The results of the present study indicate that paclitaxel activates $\mathrm{NF}-\kappa \mathrm{B}$ in human breast cancer cells through the classic NF- $\kappa \mathrm{B}$ activation signaling pathway, IKK activation and $\mathrm{I} \kappa \mathrm{B} \alpha$ degradation. Treatment of breast cancer cells with SFN suppressed paclitaxel-induced IKK activation, leading to suppression of NF- $\mathrm{\kappa B}$ activation.

A previous study (17) demonstrated that paclitaxel activates Akt, a serine/threonine protein kinase, which is a downstream target of phosphoinositide 3-kinase. In the present study, SFN downregulated paclitaxel-induced Akt activation in MDA-MB-231 cells. Similarly, previous studies have shown that treatment with LY294002, a specific inhibitor of phosphoinositide 3-kinase, resulted in enhancement of paclitaxel-induced apoptosis through suppression of $\mathrm{NF}-\kappa \mathrm{B}$ transcriptional activity $(18,19)$. Several previous studies have shown that NF- $\mathrm{BB}$ induces the expression of cyclin D1, Bcl-2 and $\mathrm{Bcl}-\mathrm{xL}(20,21)$. The results of the present study demonstrated that the protein expression levels of Bcl-2 induced by paclitaxel were decreased following treatment with SFN due to inactivation of $\mathrm{NF}-\kappa \mathrm{B}$ signaling. Furthermore, $\mathrm{Bcl}-2$ overexpression reversed the effect of combined treatment with SFN and paclitaxel on caspase-3 activity. Therefore, the inhibition of breast cancer cell viability by SFN may be mediated by the inhibition of $\mathrm{Bcl}-2$. In conclusion, SFN enhances the anti-tumorigenic activity of paclitaxel in breast cancer cells by modulating NF- $\mathrm{B}$ activation and Akt inhibition. The results of the present study indicate that combined treatment with paclitaxel and SFN is an effective clinical strategy for the treatment of breast cancer.

\section{Acknowledgements}

The present study was supported by a Daegu University 2012 Research Grant (Daegu University, Gyeongsan, Korea).

\section{References}

1. Feuer EJ, Wun LM, Boring CC, Flanders WD, Timmel MJ and Tong T: The life time risk of developing breast cancer. J Natl Cancer Inst 85: 892-897, 1993.
2. Valero V and Hortobagyi GN: Are anthracycline-taxane regimens the new standard of care in the treatment of metastatic breast cancer? J Clin Oncol 21: 959-962, 2003.

3. Wahl AF, Donaldson KL, Fairchild C, Lee FY, Foster SA, Demers GW and Galloway DA: Loss of normal p53 function confers sensitization to Taxol by increasing G2/M arrest and apoptosis. Nat Med 2: 72-79, 1996.

4. Haldar S, Chintapalli J and Croce CM: Taxol induces bcl-2 phosphorylation and death of prostate cancer cells. Cancer Res 56: 1253-1255, 1996.

5. Yu D, Liu B, Tan M, Li J, Wang SS and Hung MC: Overexpression of c-erbB-2/neu in breast cancer cells confers increased resistance to Taxol via mdr-1-independent mechanisms. Oncogene 13: 1359-1365, 1996.

6. Pianetti S, Arsura M, Romieu-Mourez R, Coffey RJ and Sonenshein GE: Her-2/neu overexpression induces NF-kappaB via a PI3-kinase/Akt pathway involving calpain-mediated degradation of IkappaB-alpha that can be inhibited by the tumor suppressor PTEN. Oncogene 20: 1287-1299, 2001.

7. Aggarwal BB, Shishodia S, Takada Y, Banerjee S, Newman RA Bueso-Ramos CE and Price JE: Curcumin suppresses the paclitaxel-induced nuclear factor-kappaB pathway in breast cancer cells and inhibits lung metastasis of human breast cancer in nude mice. Clin Cancer Res 11: 7490-7498, 2005.

8. Pledgie-Tracy A, Sobolewski MD and Davidson NE: Sulforaphane induces cell type-specific apoptosis in human breast cancer cell lines. Mol Cancer Ther 6: 1013-1021, 2007.

9. Cornblatt B, Ye L, Dinkova-Kostova A, Erb M, Fahey JW, Singh NK, Chen MS, Stierer T, Garrett-Mayer E, Argani P, et al: Preclinical and clinical evaluation of sulforaphane for chemoprevention in the breast. Carcinogenesis 28: 1485-1490, 2007.

10. Jackson SJ and Singletary KW: Sulforaphane inhibits human MCF-7 mammary cancer cell mitotic progression and tubulin polymerization. J Nutr 134: 2229-2236, 2004.

11. Myzak MC, Hardin K, Wang R, Dashwood RH and Ho E: Sulforaphane inhibits histone deacetylase activity in BPH-1, LnCap and PC-3 prostate epithelial cells. Carcinogenesis 27: 811-819, 2006.

12. Jackson SJ and Singletary KW: Sulforaphane: A naturally occurring mammary carcinoma mitotic inhibitor, which disrupts tubulin polymerization. Carcinogenesis 25: 219-227, 2004.

13. Benedict AL, Mountney A, Hurtado A, Bryan KE, Schnaar RL, Dinkova-Kostova AT and Talalay P: Neuroprotective effects of sulforaphane after contusive spinal cord injury. J Neurotrauma 29: 2576-2586, 2012.

14. Ozes ON, Mayo LD, Gustin JA, Pfeffer SR, Pfeffer LM and Donner DB: NF-kappaB activation by tumour necrosis factor requires the Akt serine-threonine kinase. Nature 401: 82-85, 1999.

15. Wang CY, Cusack JC Jr, Liu R and Baldwin AS Jr: Control of inducible chemoresistance: Enhanced anti-tumor therapy through increased apoptosis by inhibition of NF-kappaB. Nat Med 5: 412-417, 1999.

16. Wang CY, Mayo MW, Korneluk RG, Goeddel DV and Baldwin AS Jr: NF-kappaB antiapoptosis: Induction of TRAF1 and TRAF2 and c-IAP1 and c-IAP2 to suppress caspase-8 activation. Science 281: 1680-1683, 1998.

17. Mabuchi S, Ohmichi M, Kimura A, Hisamoto K, Hayakawa J, Nishio Y, Adachi K, Takahashi K, Arimoto-Ishida E, Nakatsuji Y, et al: Inhibition of phosphorylation of BAD and Raf-1 by Akt sensitizes human ovarian cancer cells to paclitaxel. J Biol Chem 277: 33490-33500, 2002.

18. Hu L, Hofmann J, Lu Y, Mills GB and Jaffe RB: Inhibition of phosphatidylinositol 3'-kinase increases efficacy of paclitaxel in in vitro and in vivo ovarian cancer models. Cancer Res 62: 1087-1092, 2002.

19. MacKeigan JP, Taxman DJ, Hunter D, Earp HS III, Graves LM and Ting JP: Inactivation of the antiapoptotic phosphatidylinositol 3-kinase-Akt pathway by the combined treatment of taxol and mitogen-activated protein kinase kinase inhibition. Clin Cancer Res 8: 2091-2099, 2002.

20. Deeb D, Gao X, Dulchavsky SA and Gautam SC: CDDO-Me inhibits proliferation, induces apoptosis, down-regulates Akt, mTOR, NF-kappaB and NF-kappaB-regulated antiapoptotic and proangiogenic proteins in TRAMP prostate cancer cells. J Exp Ther Oncol 7: 31-39, 2008.

21. Kim JH, Gupta SC, Park B, Yadav VR and Aggarwal BB: Turmeric (Curcuma longa) inhibits inflammatory nuclear factor

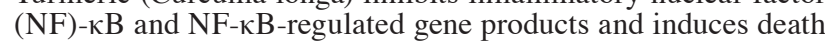
receptors leading to suppressed proliferation, induced chemosensitization, and suppressed osteoclastogenesis. Mol Nutr Food Res 56: 454-465, 2012. 